\title{
EL PSEUDORRELIEVE EN LOS VISORES DE MAPAS DE LOS GEOPORTALES IDE DE ESPAÑA
}

\author{
Miguel A. BERNABÉ-POVEDA (ma.bernabe@upm.es) ${ }^{(1)}$ \\ María Ester GONZÁLEZ-CAMPOS (geoester@gmail.com) ${ }^{(2)}$ \\ Ángeles CASTEJÓN-SOLANAS (angeles.csolanas@upm.es) ${ }^{(3)}$ \\ ${ }^{(1)}$ Prometeo en el Instituto Geográfico Militar. Quito, Ecuador ${ }^{(2)}$ Universidad \\ Nacional de Catamarca, Argentina ${ }^{(3)}$ Universidad Politécnica de Madrid, Es- \\ paña.
}

Recibido: $28 / 04 / 2015$

Aceptado: 29/07/2015

RESUMEN: Un buen número de los visualizadores de las Infraestructuras de Datos Espaciales (IDE) de las distintas Comunidades Autónomas de España, utilizan las ortoimágenes como capa base sobre la que referenciar características del territorio. Al margen de lo inadecuado de utilizar como «mapa base» una imagen aérea en lugar de un mapa general de síntesis, ocurre que estas imágenes del hemisferio norte, iluminadas por el sol desde el sur, facilitan la aparición de pseudorrelieve en un número considerable de usuarios. Esta inversión del relieve real conduce a que los valles se perciban como crestas montañosas y estas como cauces de ríos. En trabajos previos se evidenció la percepción de pseudorrelieve en más del $65 \%$ de la población al utilizar los globos virtuales tipo Google Maps. Muchos visualizadores de las IDE muestran a los usuarios la morfología del terreno a través de ortoimágenes. Con el fin de evidenciar el grado de aparición del pseudorrelieve en los visualizadores de las IDE de España, se diseñó un test basado en imágenes aéreas de las propias IDE. Los resultados previos permiten afirmar que más del $65 \%$ de los usuarios de las IDE de España no perciben adecuadamente el relieve proporcionado por las ortoimágenes utilizadas. Existen evidencias de que ese número de usuarios que perciben pseudorrelieve puede descender drásticamente a menos del $20 \%$ sin más que introducir una corrección en las ortoimágenes basada en la fusión de estas con su modelo digital de sombras. El procedimiento de fusionar con distinto grado de transparencia la capa de imagen aérea con la de su modelo de sombras (MDS) nos parece inocua pues las modificaciones introducidas en las ortoimágenes por la incorporación del MDS, no afectarán a los archivos originales sino simplemente a su visualización web. En este trabajo se muestran algunos ejemplos obtenidos de las IDE de España (IDEE) y los resultados previos del test realizado a la población. PALABRAS CLAVE: Relieve, pseudorrelieve, visualizadores IDE, inversión del relieve.

\section{THE TERRAIN REVERSAL EFFECT IN MAP VIEWER OF SPANISH SDI GEOPORTALS}

ABSTRACT: A great number of the visual displays of the Spatial Data Infrastructure (SDI) of the Autonomous Regions of Spain, use orthoimages as base layer to georeference land features. Using an aerial image instead of a synthetic map as a base map is not correct and in addition these images from the northern hemisphere illuminated by the Sun from the south lead to the perception of pseudorelief in a great number of users. This inversion of real relief makes 
valleys be perceived as mountain ridges and these as rivers. In previous papers the perception of pseudorelief was evident in more than $65 \%$ of the population when using virtual globes such as GoogleMaps. Many SDI visual displays show land morphology through orthoimages. In order to quantify the degree of pseudorelief in SDI visual displays in Spain, a test based on aerial images of the SDI was designed. First results prove that over $65 \%$ of SDI users in Spain do not perceive properly the relief provided by orthoimages. There is evidence that the number of users who perceive pseudorelief could drastically drop to $20 \%$ by just introducing a correction in the orthoimages through their conflation with their digital model of shadows. The conflation with some degree of transparency of the aerial image with their model of shadows (DMS) does not have any negative effect since the changes introduced in the orthoimages by adding the DMS will not affect the original files but only their web visualization. In this paper we show some examples obtained from Spanish SDI and the provisional results of the test carried out.

KEY WORDS: Relief; pseudorelief; visual displays of the Spatial Data Infrastructure (SDI), Relief inversion.

\section{INTRODUCCIÓN}

En trabajos anteriores (BERNABÉ y ÇÖLTEKIN, 2014; BERNABÉ y GONZÁLEZ, 2015), se demostró que se creaba espontáneamente pseudorrelieve en una mayoría de los observadores de las imágenes aéreas del hemisferio norte a través de GoogleMaps y en otros globos virtuales como YahooMaps, OpenGlobe, EarthBrowser, MicrosoftBing y AppleMaps (BERNABÉ y GONZÁLEZ, 2015). Este fenómeno de la inversion del relieve, está bien documentado desde hace muchos años (WOOD, 1968; ARNHEIM, 1976) y ocurre cuando el paisaje está iluminado desde el sur (y el usuario del mapa o de la imagn tiene el norte situado en la parte superior de la hoja o pantalla de visualización). Esa situación ocurre siempre en las imágenes aéreas del hemisferio norte y, en ciertas épocas, entre los trópicos. También ocurre en la visualización del relieve lunar (WU et al., 2013) y planetario (PAIN Y ClARKE, 2009). Dado que estos globos virtuales y otras herramientas similares se utilizan en algunos de los geoportales como «capa base» para mostrar otras características del territorio, se ha preparado una prueba para evidenciar el grado de percepción del pseudorrelieve en los usuarios que utilizan los visualizadores de los geoportales de las Infraestructuras de Datos Espaciales (IDE) de las Comunidades Autónomas de España.

Hay que considerar que las IDE son sistemas que deben fomentar el uso de la información geográfica a todo tipo de usuarios, sin importar el grado de experiencia que tengan en su manejo o uso. Al visitar cada uno de los geoportales, se comprueba que la percepción del relieve no siempre tiene resultados satisfactorios y dada la importancia que tiene esta característica del territorio, el visualizador debería incluir por defecto alguna corrección o disponer de herramientas que eviten los errores perceptivos. Por otro lado, llama la atención el uso de mosaicos de ortofotos o de imágenes satelitales como sustitutos 
de un «mapa base». Eso podría entenderse como un deseo de ofrecer sin ningún tipo de dudas la morfología del terreno tal y como es, suponiendo que las imágenes aéreas proporcionen más información que la ofrecida por un mapa de síntesis general en el que se muestren las características generales del territorio. Sin embargo, ni las imágenes aéreas pueden sustituir a un mapa general ni puede apreciarse el relieve real a la escala de «toda la comunidad en pantalla» $\mathrm{o}$ «toda la povincia en pantalla». El pseudorrelieve (o inversion del relieve o efecto topográfico), ha sido estudiado con anterioridad (IMHOF, 1967 y 1982) y sus efectos y correcciones ya fueron estudiados en trabajos que proponían soluciones (SARAF et al., 1996; SARAF et al., 2007; BERNABÉ et al., 2011).

En este trabajo se ha realizado un recorrido por los visualizadores disponibles en los geoportales de las IDE de España y se muestran imágenes que pretenden evidenciar la existencia de problemas de percepción del relieve. Se ha querido realizar ese recorrido como lo haría un usuario nuevo y no experto en información geográfica, para conocer la facilidad o dificultad para percibir el relieve de la region de una manera adecuada, desde el nivel regional al nivel más cercano.

Para cuantificar el grado de percepción correcta del relieve en los usuarios de las IDEE, se diseñó un test, que se encuentra aún en fase de captación de datos, basado en imágenes de los visualizadores de las propias IDE. Los resultados iniciales del test nos permiten afirmar que hay un número muy considerable de usuarios que no perciben correctamente el relieve debido a la iluminación desde el sur de las imágenes aéreas del hemisferio norte.

\section{EL RELIEVE EN LOS VISUALIZADORES DE LAS IDE DE ESPAÑA}

El relieve es una de las características del terreno que más condiciona las actividades económicas y sociales de la población. Desde sus inicios, la cartografía ha puesto interés en representar los ríos y las cadenas montañosas que, junto a los límites de las costas, son las características que mejor definen un territorio. Representar adecuadamente los accidentes del relieve y facilitar su percepción a los usuarios de los geoportales es un requerimiento que deben asumir los visualizadores de las IDE. Para conocer cómo se muestra el relieve a los usuarios del geoportal, se ha realizado un recorrido por las IDE de las Comunidades Autónomas. El objetivo de ese recorrido era disponer de una idea general de cómo es comprendido el relieve por los usuarios de las IDE y saber si los visualizadores que ofrecen las distintas IDE proporcionan herramientas que permitieran al usuario ser consciente del relieve real de las imágenes aéreas. 


\section{II.1. Geoportal de la IDE de Galicia}

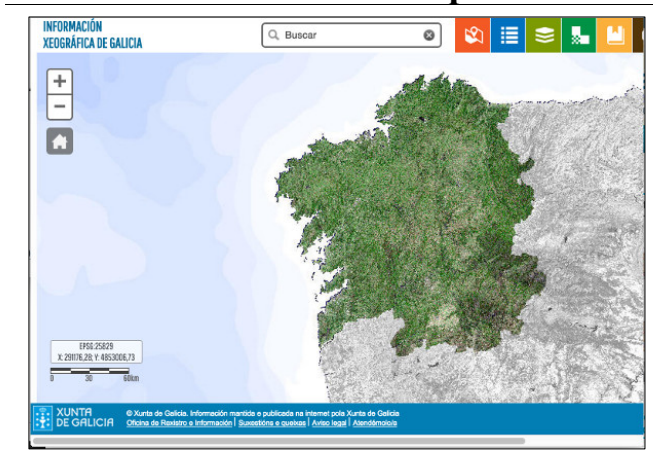

Figura 1. No es fácil percibir a esta escala cómo es la generalidad del relieve de Galicia

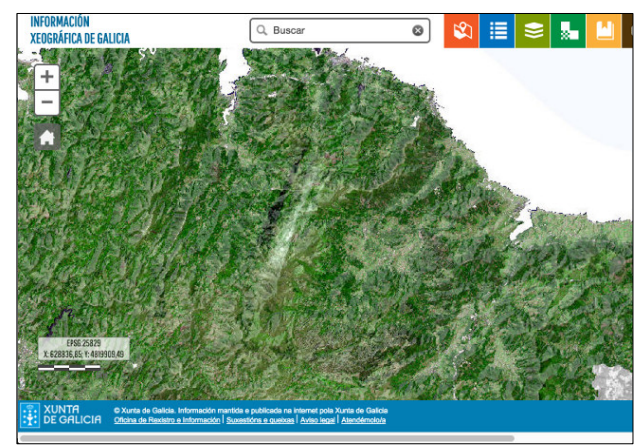

Figura 2. Aunque a esta escala el relieve se percibe, hay que preguntarse qué porcentaje de la población lo percibe correctamente

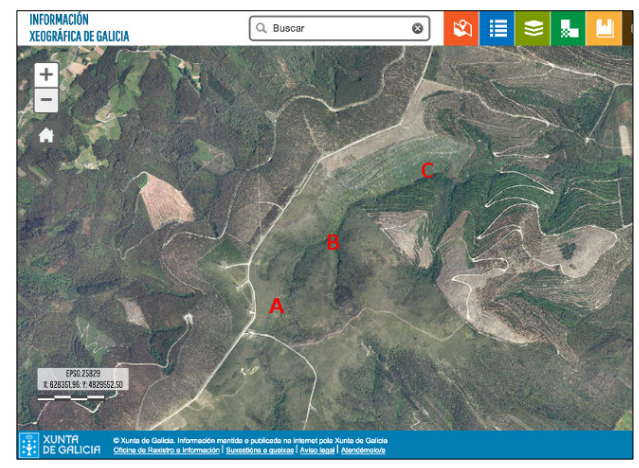

Figura 3. En pruebas similares, más del 65\% de la población percibiría ABC como una línea divisoria
El Geoportal de la IDE de Galicia (http://mapas.xunta.es/portada) se inicia con una imagen de la totalidad del territorio que aporta muy poca información sobre el relieve real (FIGURA 1).

Conforme se amplía la escala de visualización utilizando el zoom+, llegando a una visualización «subprovincial», el relieve va haciéndose más perceptible (FIGura. 2). Sin embargo, hay que preguntarse acerca del grado de percepción correcta que esas imágenes proporcionan a la población. En los trabajos anteriores (BERNABÉ-POVEDA y ÇÖLTEKIN, 2011 y 2014) se demostró que imágenes similares a la FIGURA 3, pertenecientes a territorios del hemisferio norte, proporcionaban un relieve inverso a más del $65 \%$ de la población, llegando en muchos casos a más del $85 \%$. 


\section{II.2. El servidor de mapas de SITPA-IDE, Asturias}

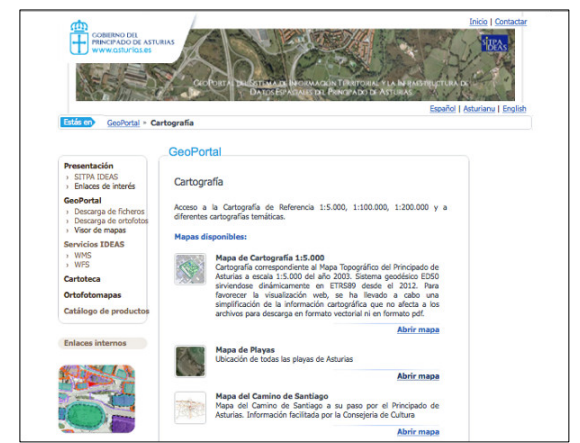

Figura 4. En la columna de la izquierda aparece la entrada a un visor de mapas

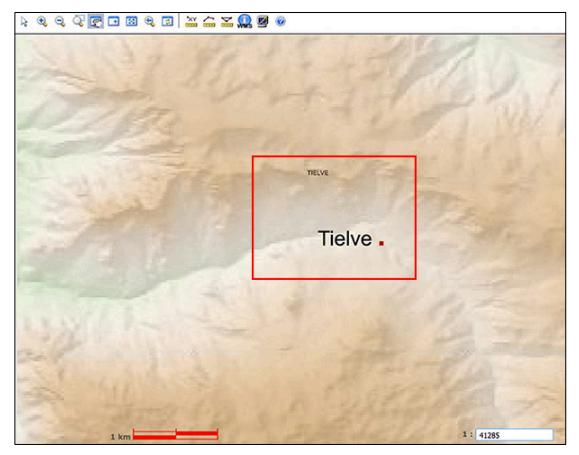

Figura 5. Relieve real por medio de un modelo de sombras. El recuadro corresponde a la FIGURA 6

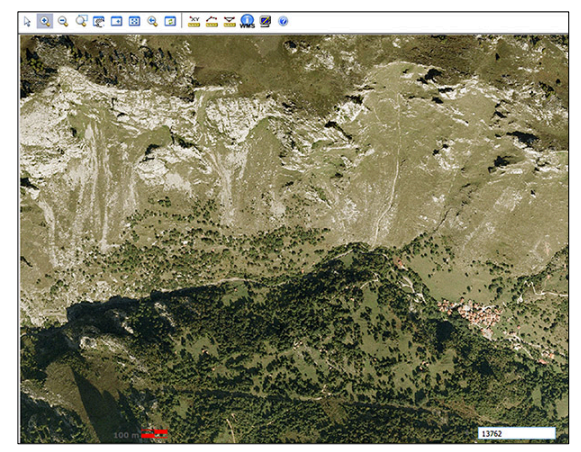

Figura 6. Al acceder a la ortofoto, el relieve parece invertirse respecto al que muestra el recuadro de la FIGURA 5
El servidor de mapas del SITPAIDE de Asturias (http://sitpa.carto grafia.asturias.es) se abre con una colección de recursos cartgráficos (FIG. 4). Un visualizador proporciona un modelo digital del relieve con hipsografía en el que apenas hay otra información más que el relieve y una toponimia elemental indicando el municipio (FIG. 5). Se ha añadido para este trabajo el rótulo «Tielve»y el punto rojo que indica la situación aproximada de la población que se encuentra cerca del cauce de un río. La FIGURA 6 muestra una imagen aérea en la que para una parte de los visitantes, la población de Tielve parecerá encontrarse en la cresta de una cordillera. 


\section{II.3. Geoportal de Cantabria}

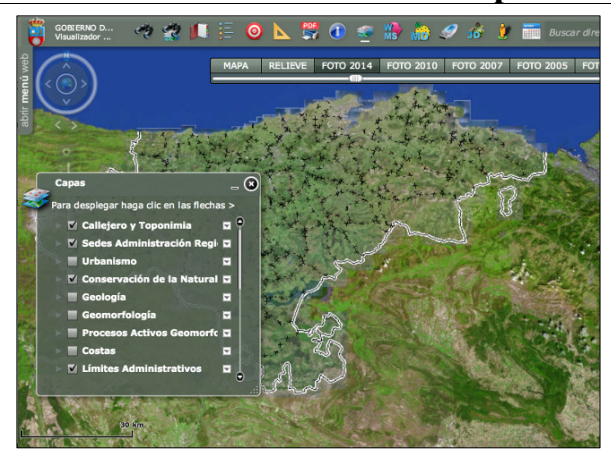

Figura 7. El relieve de Cantabria se ve enmascarado por una simbología que no aporta adecuadamente información

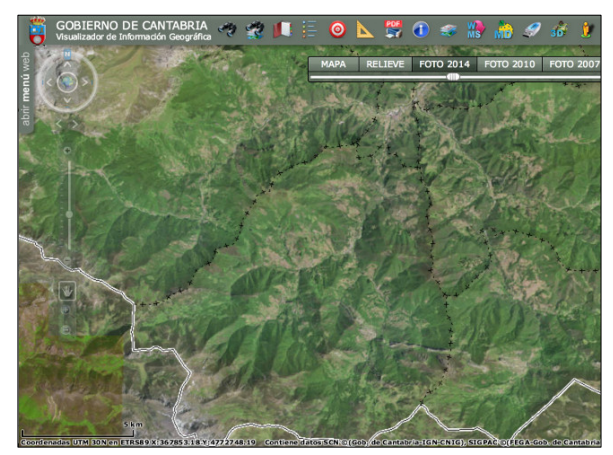

Figura 8. El potente relieve de esta imagen hay que compararlo con el de la imagen siguiente

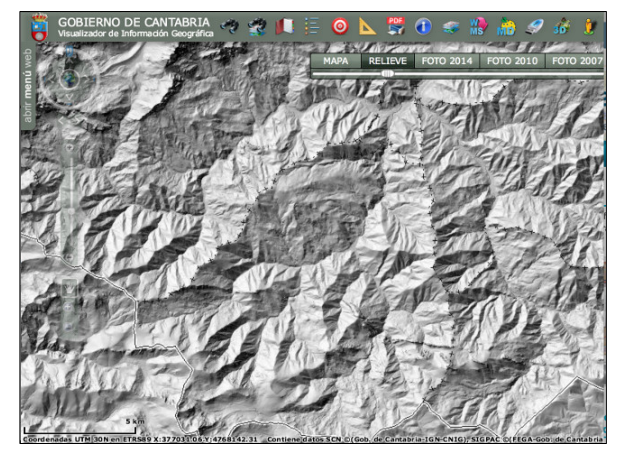

Figura 9. La imagen muestra el modelo digital de sombras de la misma zona de la figura anterior
Algo similar a lo que ocurre en Galicia, se evidencia en el geoportal de Cantabria que muestra en su página de entrada (http://mapas. cantabria.es/), una imagen aérea del territorio (FIG. 7) en la que el relieve no puede ser comprendido por el usuario debido, entre otras cuestiones, al ruido visual introducido por la simbología poco generalizada que identifica límites territoriales.

Al acercarse el usuario al territorio mediante consecutivos zoom+, aparece la morfología del relieve con más claridad (FIG. 8), pero al comparar esta morfología con la aportada por el modelo de sombras que proporciona el propio geoportal (FIG. 9) una buena parte de los usuarios tendrán la sensación de que ambas son inversas entre sí. 


\section{II.4. IDE de Euskadi}

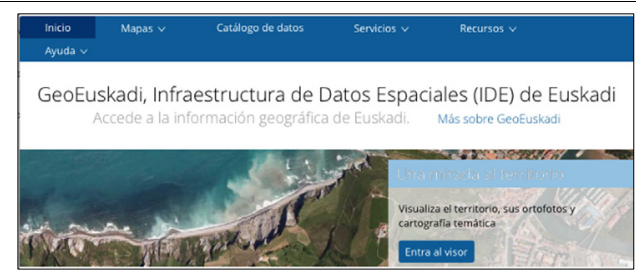

Figura 10 (a). Imagen de la página de entrada a la IDE de Euskadi (abril, 2015). Una parte de la poblacion percibirá un mar retenido por un ciclópeo muro de rocas que soporta en lo alto un camino junto al mar

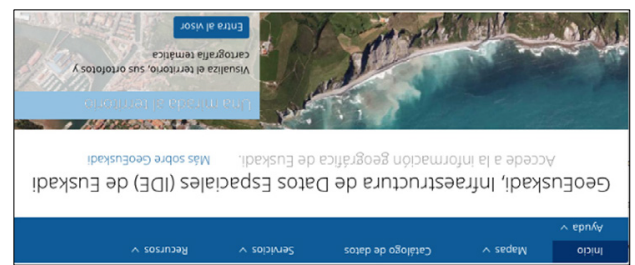

Figura 10 (b). La misma imagen anterior girada $180^{\circ}$. Ahora se percibe que la fotografia muestra un acantilado a cuyo pie hay una playa.

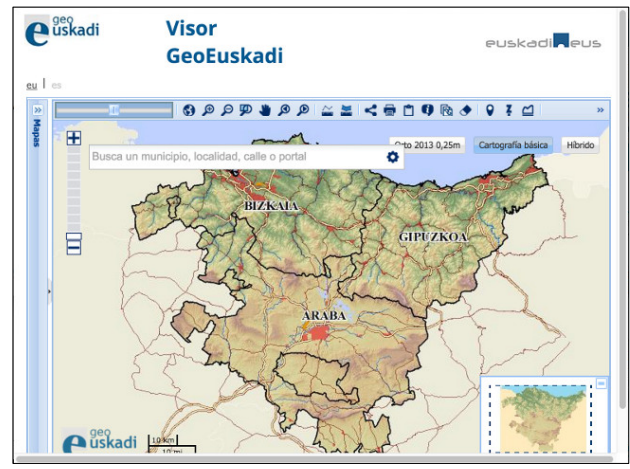

Figura 11. El mapa general muestra limpiamente el relieve de Euskadi y otras características del territorio
Con referencia a la comprensión del relieve, la página de inicio de la IDE de Euskadi muestra una imagen de difícil lectura (http:// www.geo.euskadi.eus) (FIG. 10 a). Lo que una mayoría percibirá será un enorme dique que sostiene las embestidas de un mar situado mucho más alto que el territorio al que está a punto de inundar. La situación y fortaleza que aportan las sombras de esa imagen conduce a que se perciba un paisaje inverso distinto al que se percibiría si la imagen se girara $180^{\circ}$ (FIG. $10 \mathrm{~b}$ ).

El visor de mapas de Geoeuskadi que se ofrece en esa página, no utiliza las imágenes aéreas por defecto sobre las que situar características topográficas, sino que utiliza una cartografía de su territorio en la que, de un golpe de vista (FIG. 11), el usuario puede hacerse fácilmente una idea del relieve. 


\section{II.4. (bis) IDE de Euskadi}

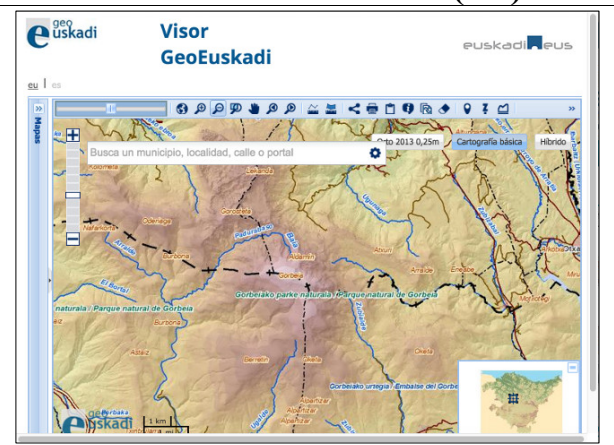

Figura 12. La hipsometría sobre el modelo digital de sombras (MDS) proporciona una imagen fácil de leer

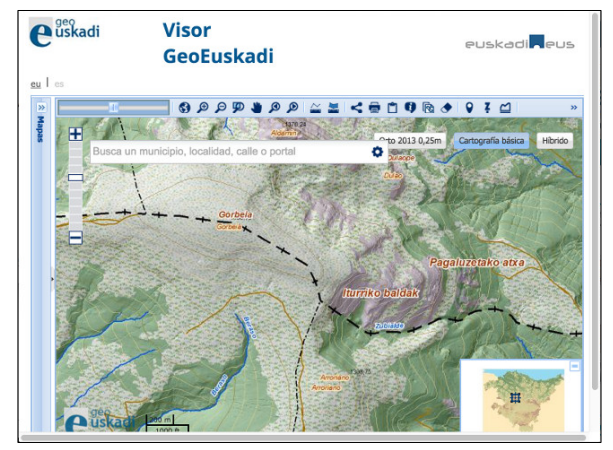

Figura 13. Monte Gorbea. El MDS no impide la incorporación sobre él, de otras características del territorio

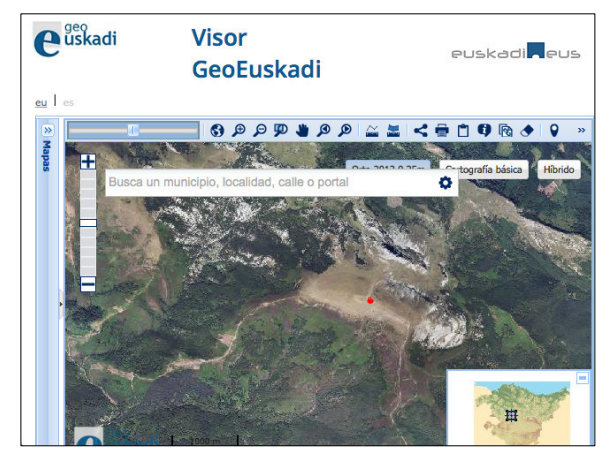

Figura 14. Monte Gorbea (cumbre con un punto rojo). ¿Se puede identificar el relieve de esta imagen con el de la FIG.13?
Conforme el usuario se acerca se obtiene una información más precisa del relieve (FIG. 12) llegando a visualizarse las curvas de nivel (FIG. 13). El visor de Geoeuskadi también permite visualizar las ortoimágenes (FIG. 14) y como ocurre en la mayoría de los geoportales, las imágenes aéreas o las satelitales no se proporcionan corregidas de pseudorrelieve por alguno de los métodos documentados (SARAF et al. 1996; SARAF el al, 2007; BERNABÉ-POVEDA y ÇÖLTEKIN, 2014). 


\section{II.5. IDE de Navarra}

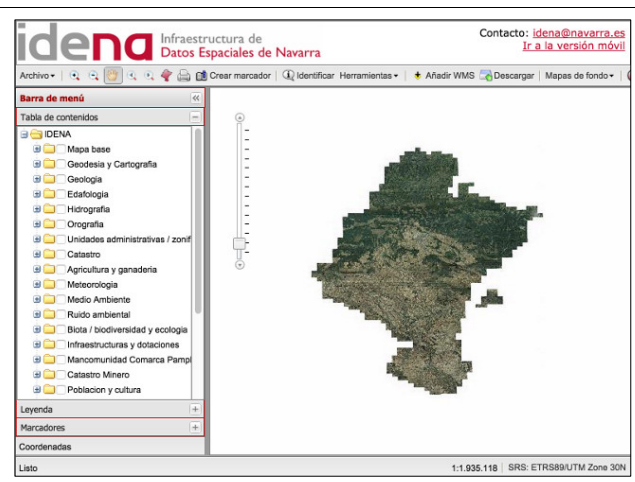

Figura 15

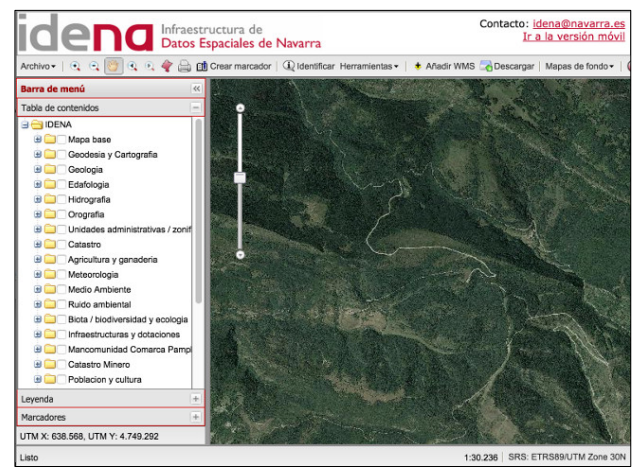

Figura 16

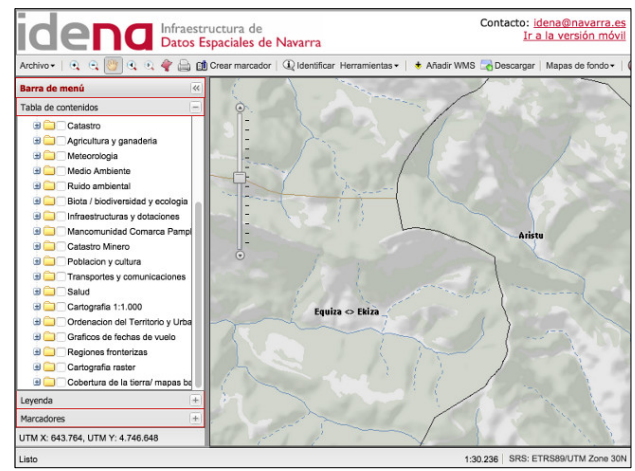

Figura 17. La misma zona que la FIGURA 16. Analicese la diferencia de relieves
Es de sobra conocido que el uso de las imágenes aéreas como sustitutas de un mapa base que ayude al usuario a hacerse una idea general del territorio, no es adecuado. El mapa es una síntesis de la diversidad de características más importantes que definen un territorio y la imagen aérea no puede sustituir al mapa como comunicador de esa síntesis.

La IDE de Navarra, (http://ide na.navarra.es/) (FIG. 15), inicia el recorrido visual por la comunidad proporcionando un mosaico de imágenes aéreas. Conforme se acerca el usuario al territorio, aparece más claramente el relieve aparente (FIG. 16) constatando que, para una buena parte de los usuarios, el relieve proporcionado por esta imagen será inverso al que se presenta en la FIGURA 17, correspondiente al modelo de sombras de la misma zona y también ofrecido por el mismo geoportal. 


\section{II.6. IDE de La Rioja}

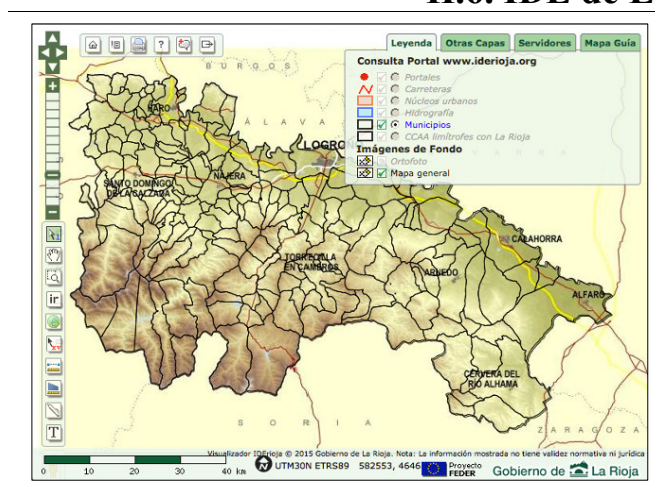

Figura 18

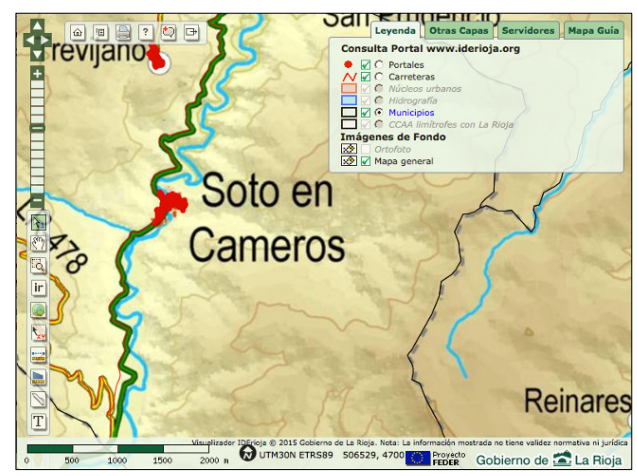

$\underline{\text { Figura } 19}$

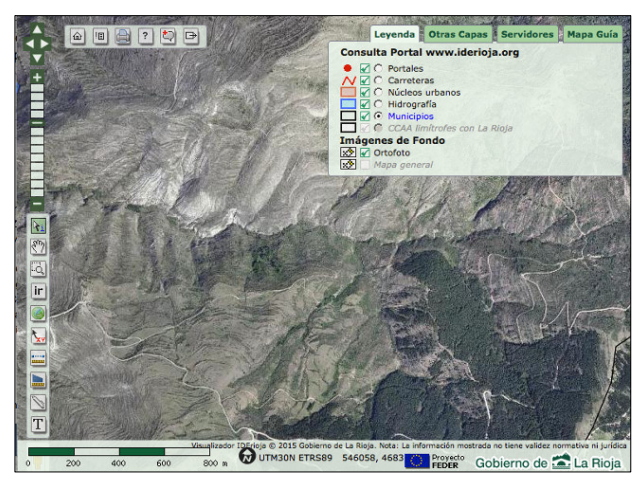

La IDE de La Rioja (http:// www.iderioja.larioja.org/) dispone de varios visores de cartografía. Uno de ellos, el denominado GeoVisor, utiliza por defecto una imagen aérea sobre la que se marcan los límites administrativos y algunos topónimos. Las imágenes de este visor pueden conducir a la percepción del mismo pseudorrelieve que los mostrados hasta ahora en párrafos anteriores.

Sin embargo, otro visor denominado Visualizador Regional (FIG. 18), muestra por defecto una imagen de la comunidad autónoma utilizando un mapa con un modelo de sombras que realza el relieve. Este visualizador permite hacer zoom+ $\mathrm{y}$ acercarse progresivamente al terreno (FIG. 19) hasta que después de algunos zoom aparece la ortofoto (FIG. 20) que en muchos casos, como el que se muestra, conducirá también a una mala interpretación del relieve al no disponer de correctores de pseudorrelieve.

Figura 20 


\section{II.7. IDE del Gobierno de Aragón}

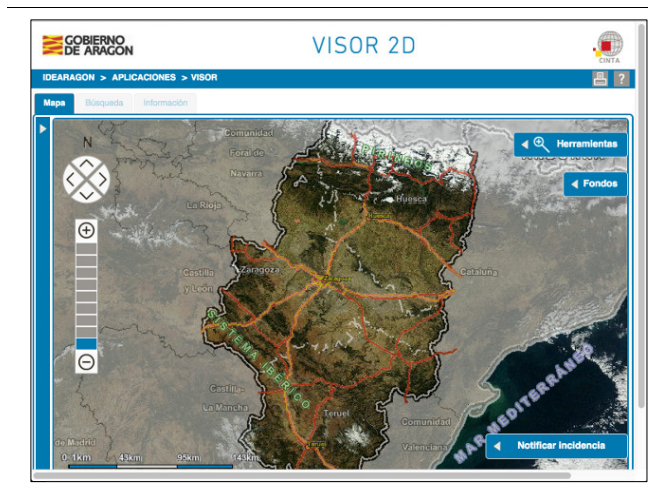

Figura 21

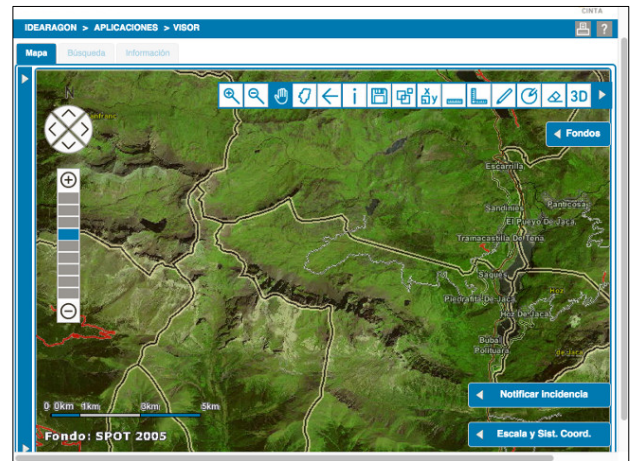

Figura 22

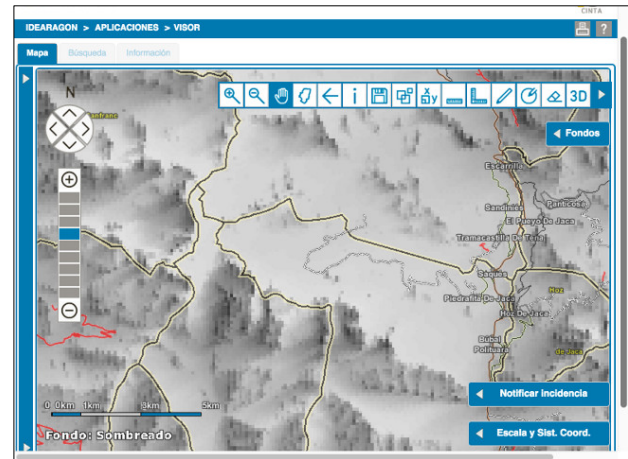

Figura 23
Como en otros muchos casos, la página de inicio del visor 2D de la IDE del Gobierno de Aragón http: //idearagon.aragon.es/ (FIG. 21) utiliza la imagen de la región procedente de sensores. En este caso del sensor MODIS, sobre la que se colocan algunas características principales (carreteras, ciudades).

Conforme se hace zoom+, aparecen nuevos fondos (FIG. 22) a modo de nuevos «mapas base» que provienen de otras fuentes (SPOT 2005, PNOA) pero que no proporcionan una idea exacta del relieve ni, debido a la potencia cromática de las imágenes, permitan incluir información que sea fácilmente legible. Tampoco nos parece que el «fondo sombreado» que utiliza el geoportal proporcione una imagen entendible del relieve (FIG. 23). 


\section{II.8. IDE del Cataluña}

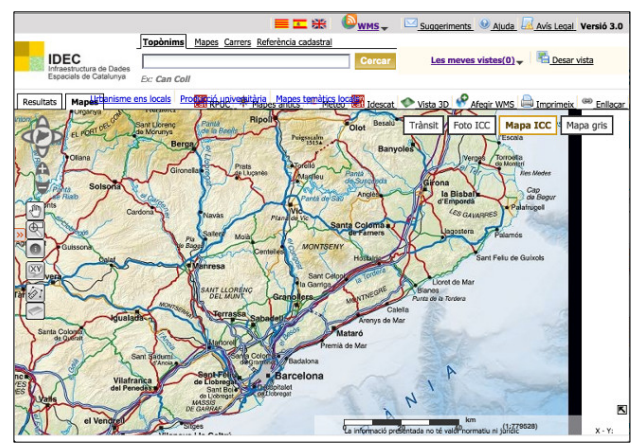

Figura 24

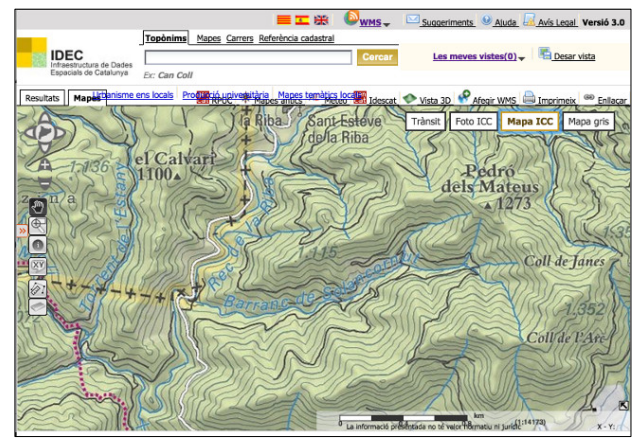

$\underline{\text { Figura } 25}$

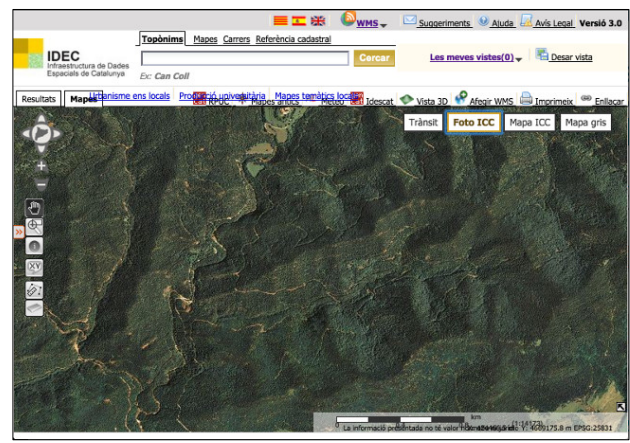

El visor de mapas de la IDE de Cataluña (http://www.geoportalidec.cat/) proporciona por defecto un mapa (FIG. 24) en el que con delicadeza está representado el relieve de la región sin que esta caracterísica impida representar otras importantes.

Conforme se acerca la visión del territorio con zoom+, aparecen distintos tratamientos del relieve, siempre como una capa auxiliar que «ayuda» a la visualización y comprensión de la geomorfología del territorio. Los distintos zoom del visor, proporcionan la posibilidad de elegir, entre otras visualizaciones, la que se denomina «Mapa ICC» (FIG. 25) y la que se denomina «Foto ICC» (FIG. 26). Queremos incidir en la comparación de estas dos imágenes que muestran la misma zona para ser conscientes de las diferencias que ambas pueden proporcionar en la percepción del relieve; por esta razón se sugiere corregir las imágenes de lo que también se conoce como «efecto topográfico».

$\underline{\text { Figura } 26}$ 


\section{II.9. IDE de Castilla y León}

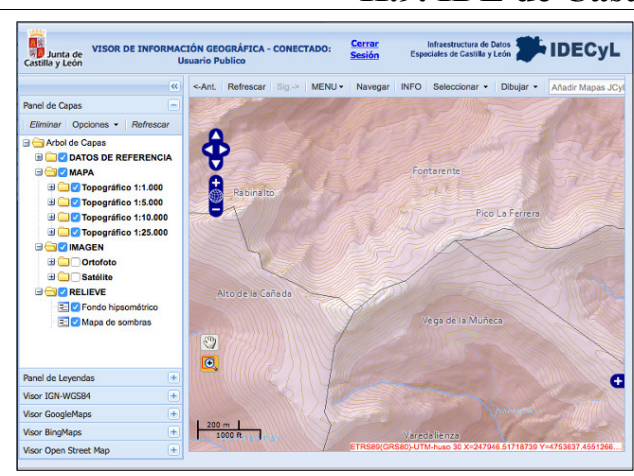

Figura 27

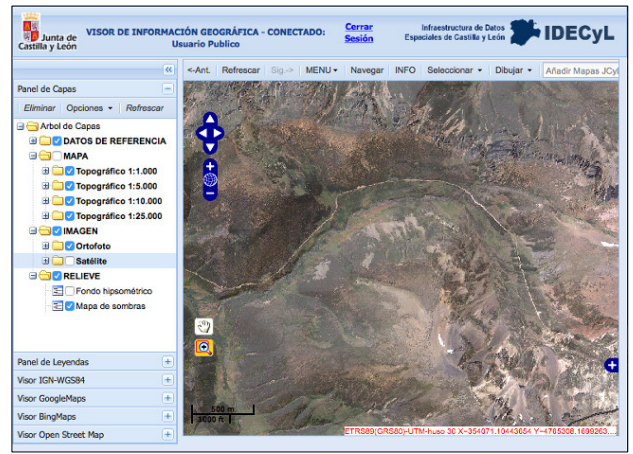

Figura 28

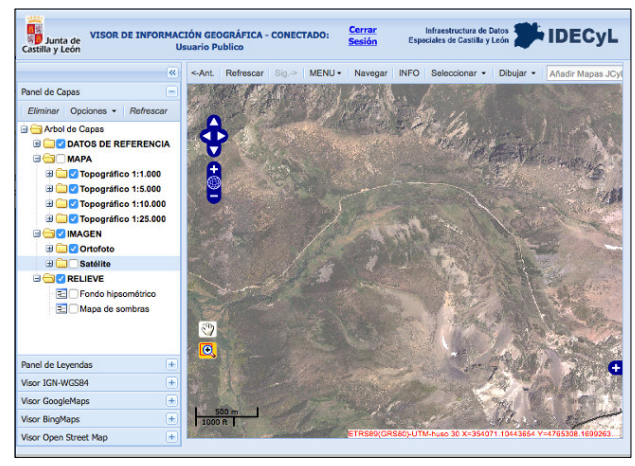

El visor de información geográfica de la IDE de la Junta de Castilla y León tiene una característica que lo distingue de cualquiera de los demás (http://www.cartografia. jcyl.es/) en cuanto a la percepción del relieve.

Esta característica es que el usuario puede fácilmente visualizar fusionadas dos capas distintas; en el caso que nos interesa, la capa del modelo digital de sombras y la capa de imagen aérea, pudiendo dotar de un grado de transparencia a una de ellas de manera que puedan verse ambas superpuestas. El resultado es una imagen aérea con mucho más relieve. El geoportal proporciona por defecto la visualización del relieve del territorio mediante la fusión de la capa de hipsometría con la capa de un modelo de sombras, a la que se incorpora con los sucesivos zoom+ la capa de curvas de nivel. (FIG. 27). Cuando el zoom es lo suficientemente cercano, aparece la fotografía del territorio en la que, también por defecto, lleva fusionada la capa del modelo de sombras (FIG. 28). Para que el lector pueda ver la diferencia perceptiva que existe cuando no está el modelo de sombras asociado, se coloca la misma figura sin el modelo de sombras (FIG. 29).

Figura 29 


\section{II.10. La Comunidad de Madrid}

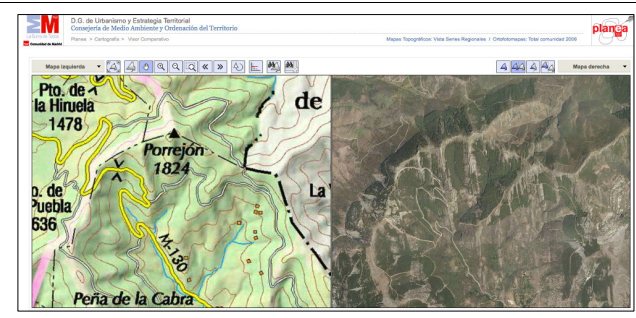

Figura 30. Es dificil situar los accidentes del territorio si no fuera por la existencia de las carreteras visibles en la imagen

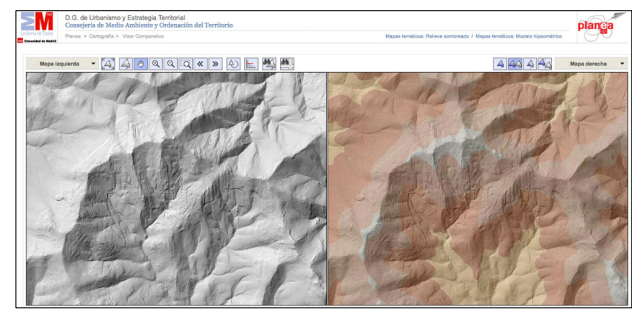

Figura 31. La hipsometría permite comparar las alturas relativas que no son visualizables fácilmente en el MDS

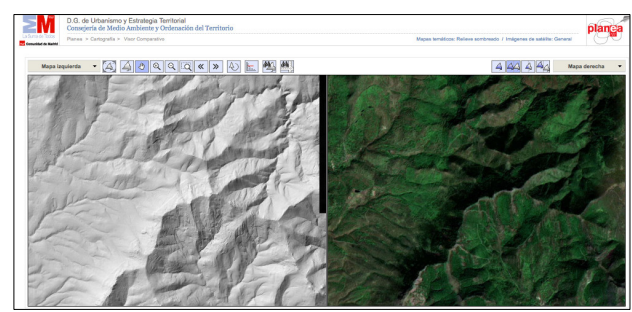

Figura 32. Consideramos que una mayoría no sería capaz de percibir el relieve real a través de la imagen de satélite
La Comunidad de Madrid (www.madrid.org/cartografia/idem ) dispone en su geoportal de diferentes visores pero, por su interés, se muestra aquí el Visor Comparativo, que permite utilizar una doble ventana en la que situar dos diferentes representaciones del mismo territorio. La potencia de las imágenes que se muestran deja en evidencia que la ortofoto (FIG. 30) no permite visualizar el relieve con la misma claridad que lo hace un mapa con su capa de sombreado.

La FIGURA 31 nos muestra el modelo digital de sombras y la capa de hipsometría de la misma zona anterior, mostrando la inversion del relieve que se produce en la ortofoto de la Figura 30. Finalmente, la figura 32 muestra las enormes diferencias perceptivas que existen entre el relieve del MDS y una imagen satelital de la misma zona. 


\section{II.11. La Comunidad de Castilla-La Mancha}

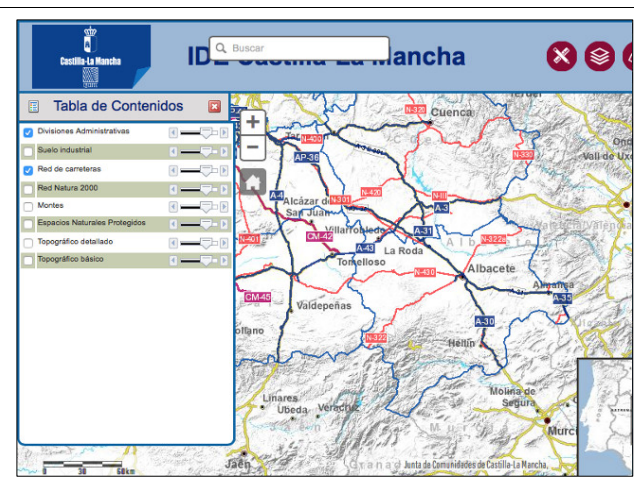

Figura 33

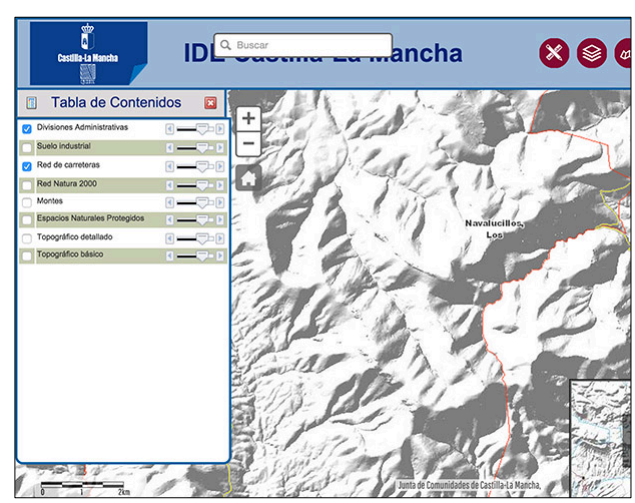

Figura 34

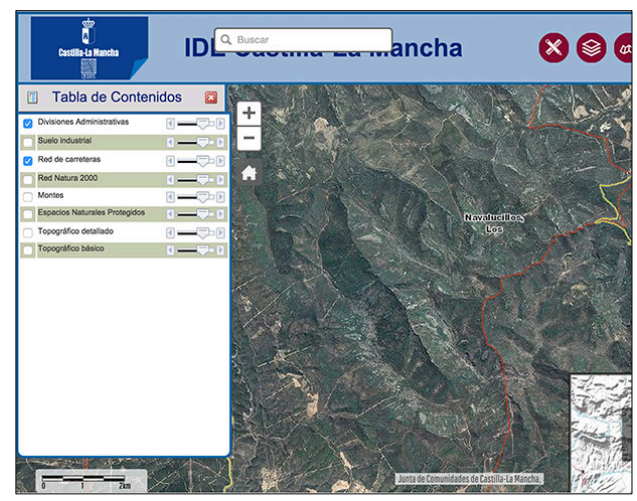

La Comunidad de Castilla la Mancha muestra por defecto un mapa base con un modelo del relieve (FIG. 33) en el que pueden incorporarse con mayor o menor grado de intensidad, distintas capas controlada por el usuario (divisiones administrativas, comunicaciones, topográfico, etc.) dotándolas, también a voluntad del usuario, de distinto grado de transparencia. El visor incorpora una simbología en la parte superior, uno de cuyos iconos dice «selección de mapa de fondo». Ahí se puede escoger la imagen del relieve (FIG. 34) o la de la ortofoto (FIG. 35). También la comparación de estas dos últimas imágenes nos mostrará las diferencias entre el relieve del modelo de sombras y la ortofoto. Acceso en: http://visores.castillalamancha.es/ide/.

Figura 35 


\section{II.12. La Comunidad Valenciana}

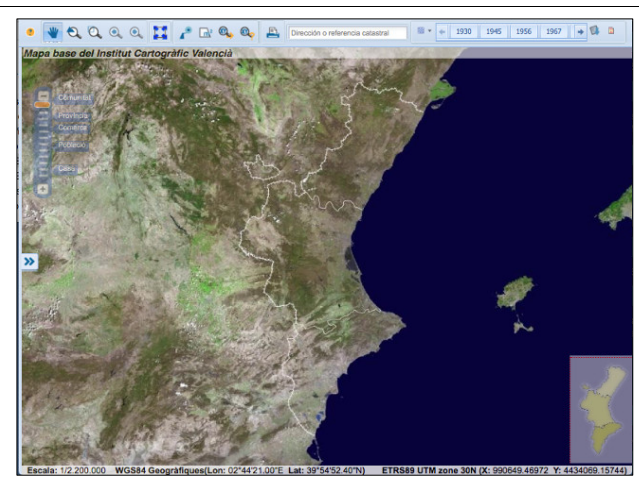

$\underline{\text { Figura } 36}$

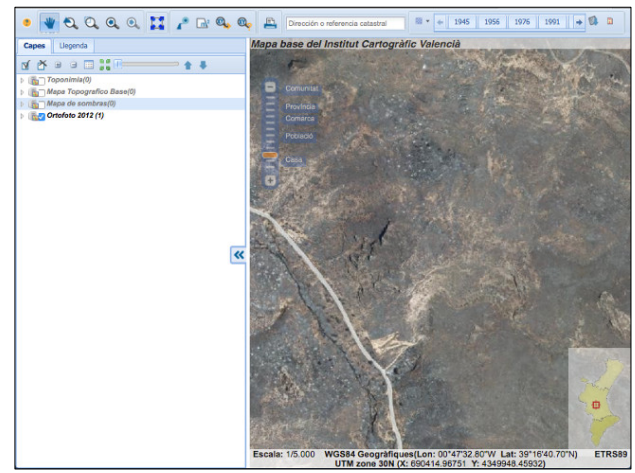

Figura 37

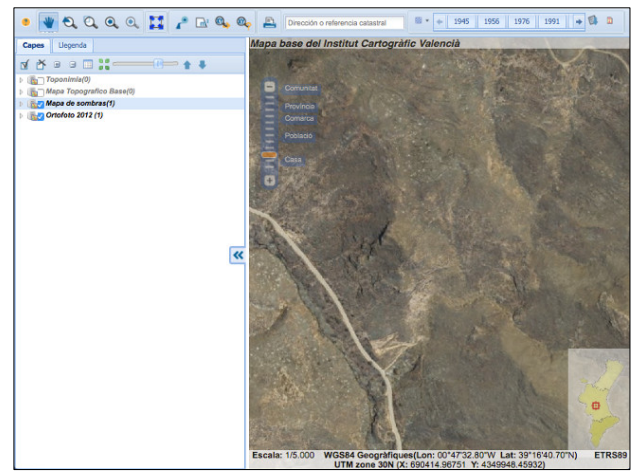

Una muestra más del uso de la imagen aérea como mapa base (FIG. 36) es la que ofrece la IDE de la Comunidad Valenciana (http:// terrasit.gva.es/). Las características geográficas que definen la región, y en particular el relieve proporcionado por esa imagen es apenas perceptible. Se vuelve a incidir en la desventaja de utilizar una imagen aérea en vez de un mapa general que sirva como «mapa base». Sin embargo, el visualizador de cartografía de la IDE Valenciana tiene una ventaja compartida con Castilla y León y es la posibilidad de incorporar el modelo de sombras conflacionándolo a las ortofotos de manera que podemos ver las mejoras perceptivas que existen gracias a estas incorporaciones (FIG. 38) frente a la imagen aérea sin esa incorporación (FIG. 37).

Figura 38 


\section{II.13. La Comunidad de Murcia}

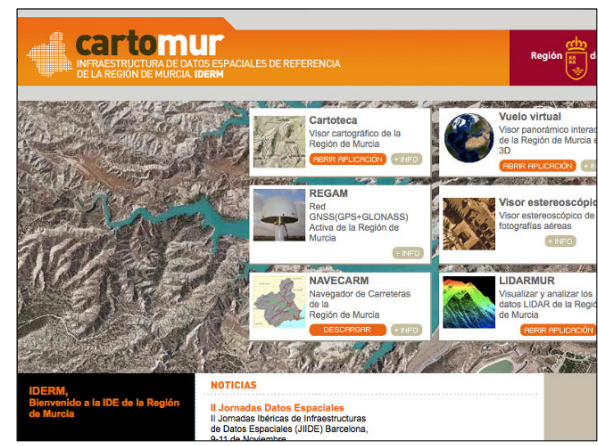

Figura 39. El modelo digital del fondo tiende a mostrar los rios por las cumbres

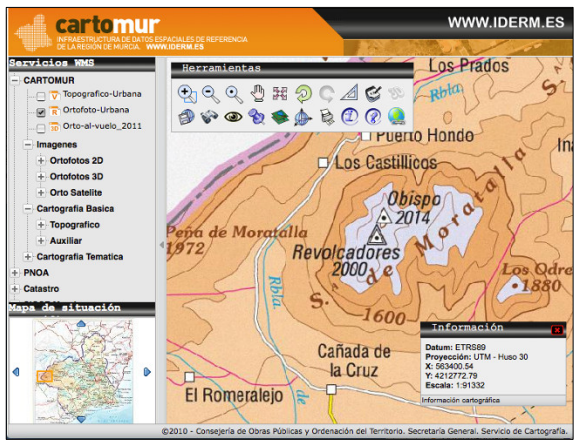

Figura 40. Relieve de la Sierra de la Moratalla en base a curvas e hipsometría

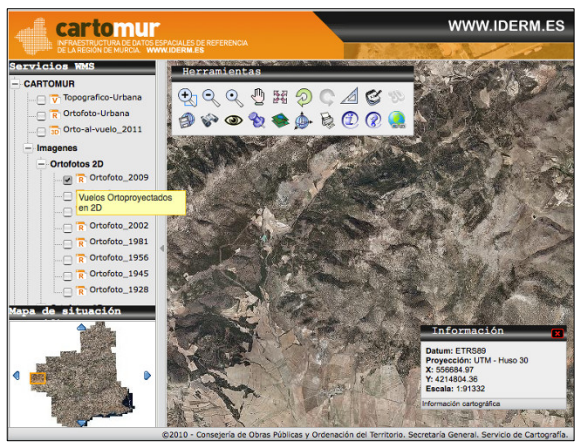

Figura 41. Misma zona que la FIGURA 40. Es dificil percibir el relieve
La potencia que tiene la imagen 2D del terreno queda patente en varios de los geoportales IDE que utilizan imágenes para evidenciar la geomorfología. Tal es el caso del geoportal Cartomur de la IDE de la Región de Murcia (http://cartomur. imida.es/) que nos muestra una imagen (FIG. 39) en la que los ríos y los pantanos serán percibidos por los usuarios corriendo por lo alto del relieve. Al acceder a la aplicación que da entrada a la cartoteca, se visualiza un mapa topográfico general, percibiéndose en los sucesivos zoom+ el relieve (FIG. 40) mediante una simbología tradicional (hipsometría, curvas de nivel y puntos acotados). La capacidad para expresar el relieve de este mapa (FIG. 40) comparada con las limitaciones perceptivas de la imagen aérea de la misma zona (FIG. 41) pone en evidencia la difícil tarea de percibir el relieve real a través de esta última posibilidad. 


\section{II.14. Extremadura}

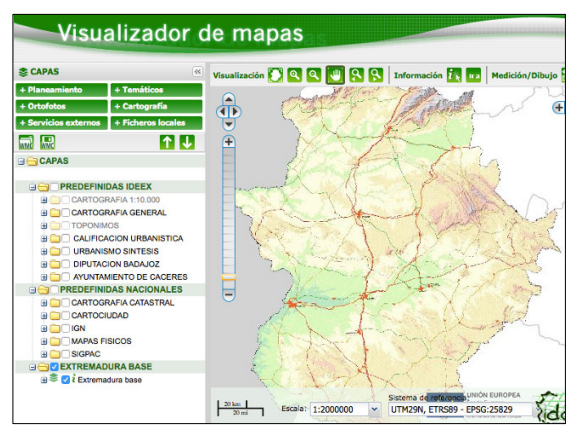

Figura 42

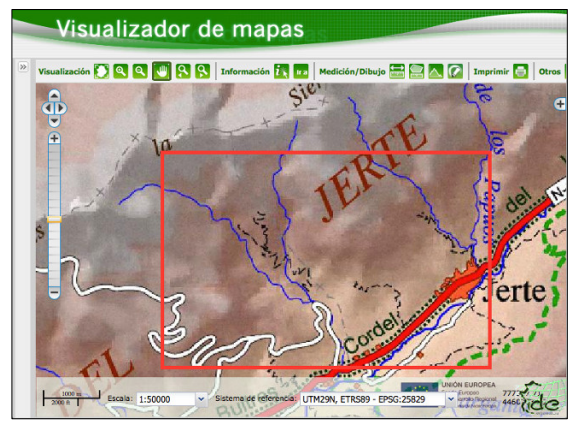

$\underline{\text { Figura } 43}$

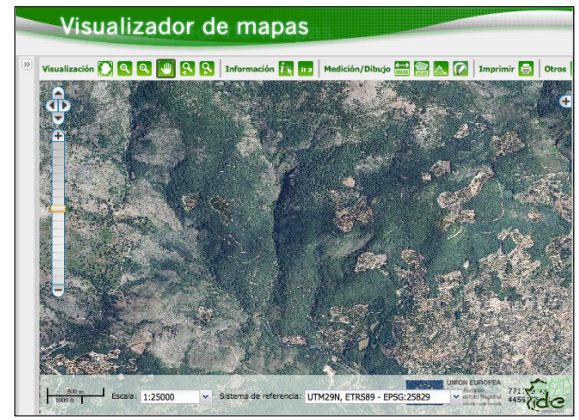

Figura 44
La clásica representación de un territorio mediante el «mapa físico» y el «mapa político», se aprecia en el deseo repetido en muchos geoportales de las IDE de España de mostrar, en una especie de mapa general, ambas características. En algunos casos las características que deben mostrarse en el mapa físico (ríos, cadenas montañosas, etc.), se materializan mediante la imagen aérea del territorio pues parece que nada mejor que la propia foto para mostrar la realidad. Sobre esta foto se incorporan posteriormente detalles del mapa político (límites administrativos, ciudades) en un intento de sustituir al mapa topográfico. En otros casos, evitando el mosaico de fotos o la imagen satelital, se utiliza un mapa en el que claramente queden expuestas las características físicas y políticas esenciales de la comunidad autónoma y que facilite la lectura y comprensión del territorio al usuario, como se hace (FIG. 42) en el visualizador de la IDE de Extremadura (http://www.ideextremadura.es/Geoport al/ ). En él puede apreciarse con limpieza tanto el relieve general como las demarcaciones políticas y los grandes núcleos urbanos, además de una red con las carreteras principales. Este modelo ofrece a los usuarios del geoportal una clara idea de la región. Como en otros geoportales, al ir haciendo zoom+ van apareciendo nuevos mapas que van mostrando el terreno con más detalle basados en escalas menores hasta que en un momento (FIG. 43) al volver a hacer zoom+ en lugar del mapa aparece por defecto la imagen aérea (FIG. 44). Se ha remarcado en rojo en la FIGURA 43 la zona correspondiente a la FIGURA 44 para ver la dificultad con la que se pueden identificar los relieves en esta última y cómo de nuevo aparece el pseudorrelieve. 


\section{II.15. IDE de Andalucía}

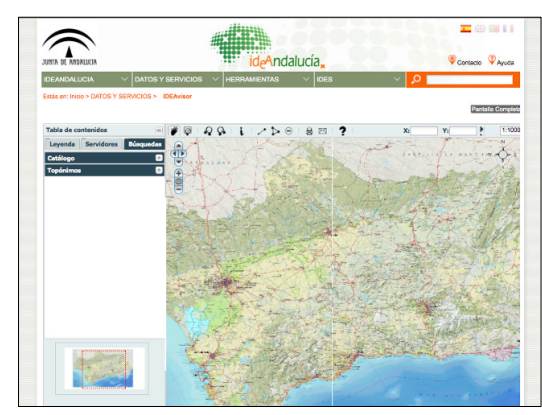

Figura 45. El mapa que se presenta en la web de entrada al geoportal de la IDE de Andalucía

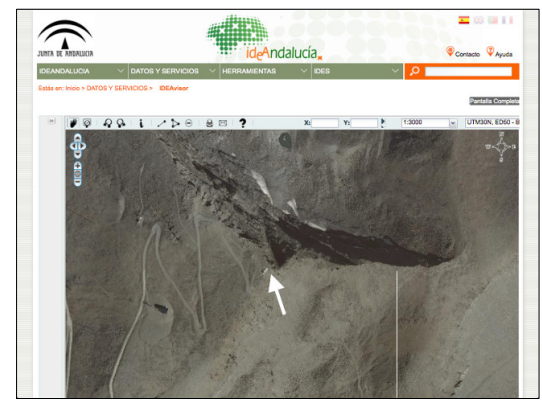

Figura 46. La flecha señala la cumbre del Veleta

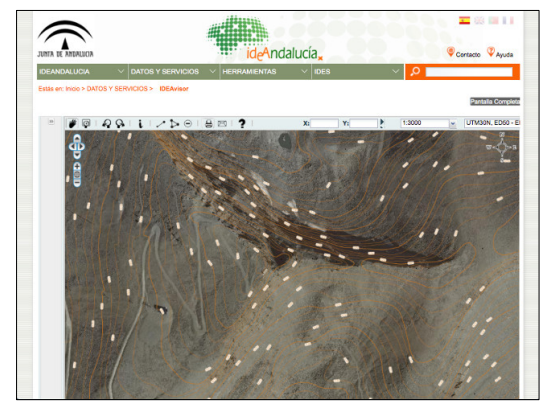

Figura 47. Las ilegibles etiquetas con la cota de las curvas no aportan facilidad de lectura
Si la utilización de una imagen aérea no es adecuada para mostrar las características morfológicas de una región, tampoco lo es la utilización de un mapa que no ha sido diseñado para ser visto en el limitado espacio de una página web. Esto ocurre con la página de inicio del IDEAVisor, (http://www.ideandalucia.es) (FIG. 45), que presenta un mapa general de la región a escala 1:400.000, diseñado para ser un mapa-papel y que aquí debe ser visto en el pequeño espacio de la pantalla de un monitor. El resultado es que quien no sepa cómo es el relieve de Andalucía, no lo verá claramente en ese mapa ni queda clara la búsqueda de topónimos, por lo que habría que cuestionarse el uso de ese mapa en ese lugar. Para encontrar el relieve de una cierta zona, el usuario debe ir haciéndo zoom+ sobre el mapa anterior (sin que éste sea consciente del nivel de zoom en el que se encuentra) hasta que en el $6^{\circ}$ zoom + aparece un mapa que corresponde al 1:25.000 con un modelo digital de fondo que proporciona una información geomorfológica comprensible. Un par de zoom + conducen al usuario al relieve del 1:10.000 que ahora aparece definido en base a curvas de nivel. En todo momento puede incorporarse, como capa base, la ortofoto de diferentes épocas. A pesar de esta posibilidad existente en el Visor, la incorporación de las curvas de nivel a la imagen aérea no ayudan en la comprensión del relieve, tan como se muestra en las FIGURAs 46 y 47 correspondientes ambas a la cumbre del Veleta. Consideramos que puesto que los visualizados están dirigidos al mayor número de usuarios, la visualización debería cuidarse para que no existieran errores perceptivos ni ruido en la comunicación visual, como por ejemplo las ilegibles etiquetas de las curvas de nivel (FIG. 47). 


\section{II.16. Visualizador IDE de las Islas Baleares}

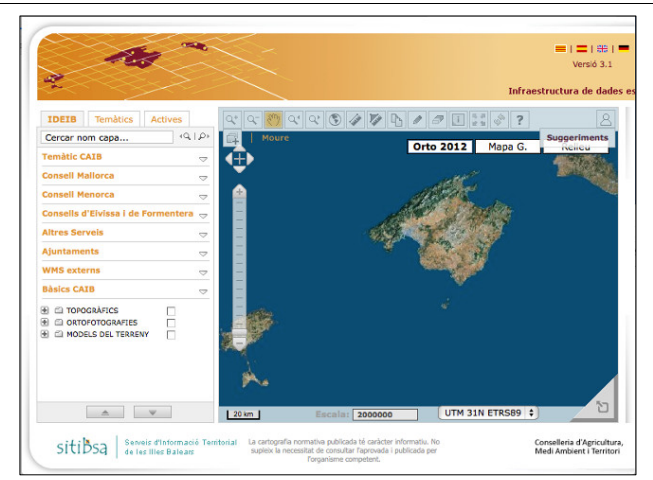

Figura 48

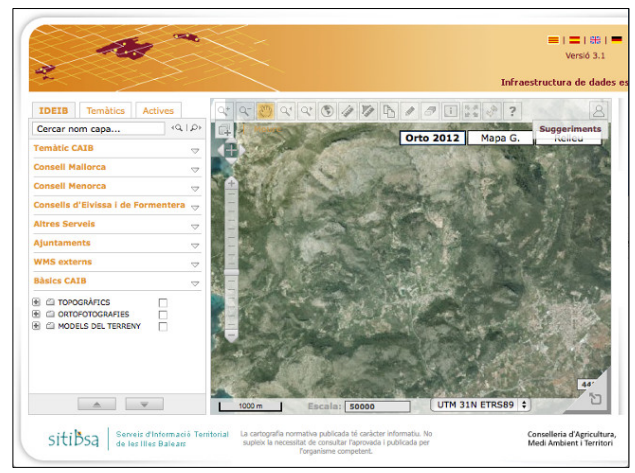

Figura 49

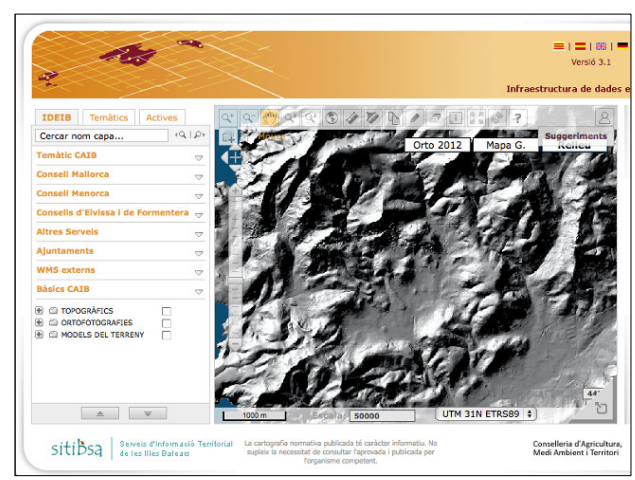

Figura 50
El visualizador por defecto de la IDE de las Islas Baleares (http:// www.ideib.cat/), muestra una imagen en la que el relieve es visible (FIG. 48). En este caso, se pueden observar claramente las zonas montañosas e intuir la orografía. Como en el caso de Cataluña, el visualizado viene por defecto con pestañas que permiten visualizar distintas capas. En el caso de la pestaña «Orto 2012» (FIG. 49) a partir del $6^{\circ}$ zoom, la imagen que aparece no permite distinguir claramente el tipo de relieve que corresponde. Abriendo la pestaña «Relieu» puede verse el relieve proporcionado por un modelo digital de sombras (FIG. 50) y claramente distinguirse la potencia de la imagen frente a la planicidad de la ortofoto. 


\section{II.17. Visualizador IDE de Canarias}

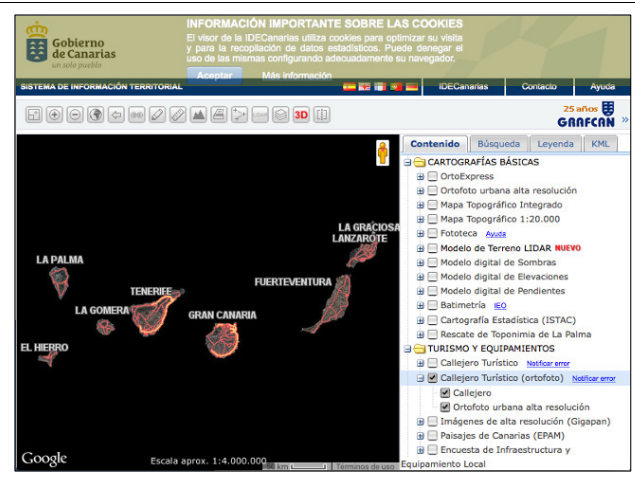

Figura 51

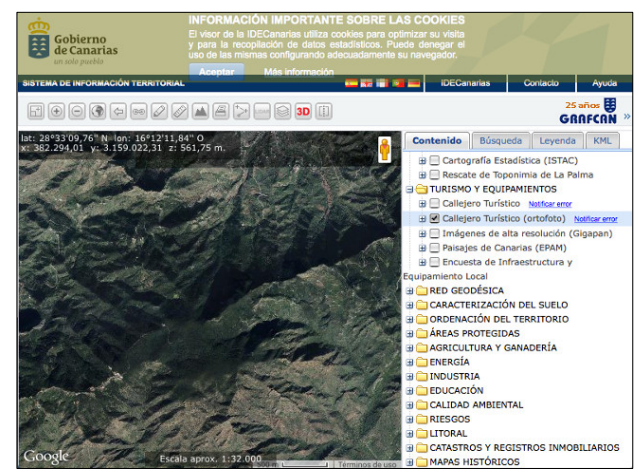

Figura 52

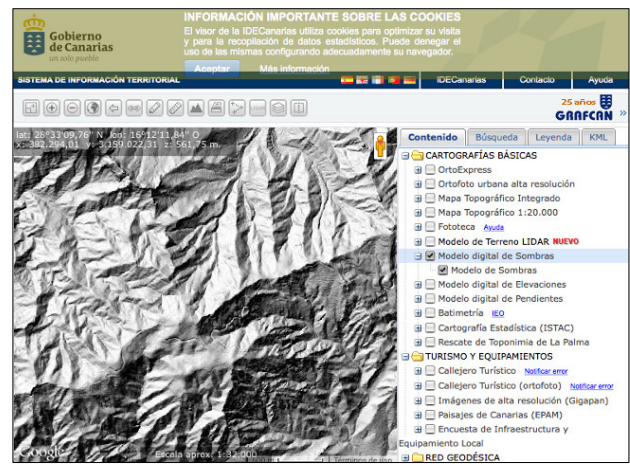

Figura 53
El visor de inicio de la IDE de Canarias (http://www.idecanarias. es/) apenas proporciona otra información que la situación relativa de las islas y su nombre (FIG. 51). El visualizador está basado en Google y como éste, exhibe las mismas características relacionados con el pseudorelieve. Haciendo zoom sobre una zona extremadamente movida, como es la cordillera de Anaga en el noreste de la isla de Tenerife (FIG. 52) y evitando ver la costa para no dar pistas a la percepción, la imagen que muestra la afilada cresta de la cordillera nada tiene que ver con la morfología que presenta su modelo digital de sombras, que para una gran parte de la población, ofrecerá un relieve inverso (FIG. 53). 


\section{EVALUACIÓN DEL PSEUDORRELIEVE. DISEÑO Y APLICA- CIÓN DE UN TEST A TRAVÉS DE INTERNET.}

Para evidenciar y cuantificar la creación espontánea del relieve inverso en la población que visita los geovisores de las IDE de España, se diseñó un test basado en imágenes de las propias IDE. Puede accederse al test en: http://goo.gl/cw4A4n

El test tiene las siguientes características:

1. Se muestran 20 imágenes vía internet de relieves provenientes de los visualizadores de las IDE de España. No pudo incluirse el visualizador de Cataluña por no estar disponible los días del diseño de la prueba (marzo, 2015).

2. Para evitar que se pierda la espontaneidad en las respuestas, se informa al participante que el tiempo total para realizar el test es de 5 minutos, esto es, unos 10 segundos por imagen. Con este test no se busca que los usuarios respondan tras analizar detenidamente las imágenes sino que lo hagan tras la impronta que éstas proporcionan.

3. Quince imágenes (números 1, 2, 3, .., 14 y 18), una por comunidad autónoma, son capturas de pantalla de los visualizadores de las IDE. Se pide que se identifique si una característica dada, definida mediante letras $(A, B, C, D, \ldots)$ es una vaguada o una cresta montañosa o se pide decir si un punto A está en un terreno más alto que otro $\mathrm{B}$, o se solicita indicar si lo recuadrado es una montaña o una depresión.

4. Una de ellas, la imagen número 15 , presenta el relieve que proporciona la IDE de Castilla y León, una de las pocas que ofrece el relieve fusionando el modelo digital de sombras con la imagen aérea.

5. Dos de ellas, la 16 y la 17 son las imágenes 10 y la 2 , volteadas $180^{\circ}$ para percibir el relieve verdadero.

6. Una de ellas, la número 19 corresponde a la imagen de Google Maps del lugar donde el copiloto de un avión de una línea aérea alemana lo había estrellado unos días antes de diseñar el test.

7. La número 20 corresponde a la 19 girada $180^{\circ}$.

8. Se ha utilizado el formulario de Google Drive para diseñar la encuesta y dar acceso a los participantes.

9. Se ha limitado el número de veces que cada usuario puede realizar el test de manera que desde la misma cuenta de Google solo se puede hacer una vez.

10. Se envió la URL al entorno de los conocidos de los autores; muchos de ellos, pero no todos, relacionados con la información geográfica. Se les solicitó que hicieran el test y que avisaran a otras personas de su entorno que quisieran hacerlo, de manera que aunque la componente académica 
de los participantes fuera alta, la componente profesional fuera variada. 11. A cada participante se le solicitó información acerca de (a) su más alto grado académico; (b) sexo; (c) lateralidad (diestro o zurdo); (d) institución de pertenencia; (e) edad y (f) país de residencia.

12.El test se mantiene activo en Internet recogiendo datos de nuevos participantes.

Las 20 imágenes y las cuestiones del test son las siguientes (en el pie de figura se remarca en negrita la respuesta correcta solo para el lector de este trabajo):
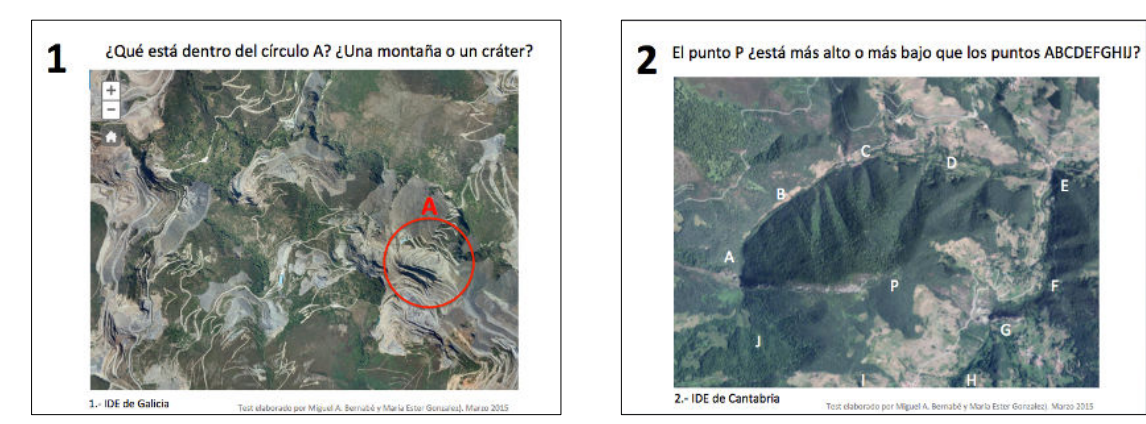

Figura 54. ¿Qué está dentro del círculo A una montaña o un crater?

Figura 55. ¿Está el punto $\mathrm{P}$ más alto $\mathrm{o}$ más bajo que los puntos $\mathrm{ABCDEFGHI}$ ?
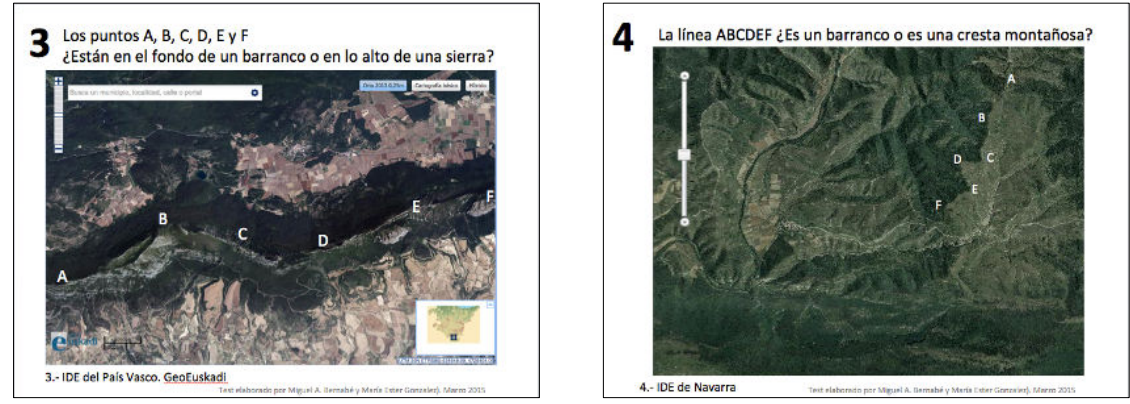

Figura 56. ¿Están los puntos A...F en el fondo de un barranco o en lo alto de Figura 57. ¿Es la línea $\mathrm{ABCDEF}$ un una sierra? 

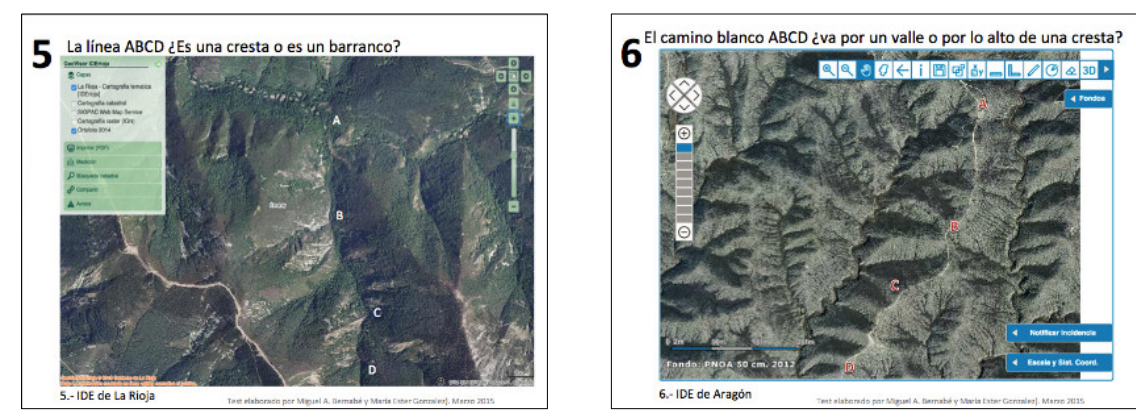

Figura 58. ¿Es la línea ABCD una cresta o un barranco?

Figura 59. ¿El camino ABCD discurre por un valle o por lo alto de una cresta?
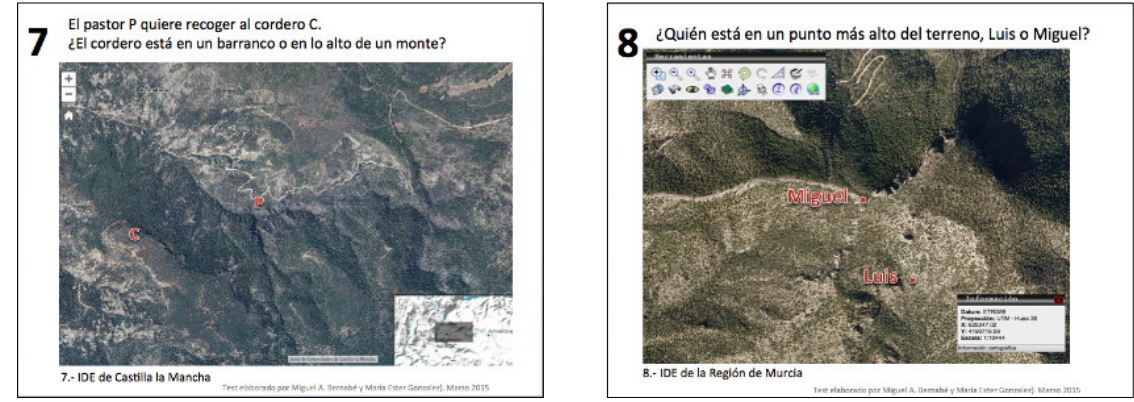

Figura 60. ¿El cordero $\mathrm{C}$ está en un barranco o en lo alto del monte?

Figura 61. ¿Quién está en un punto más alto, Luis o Miguel?
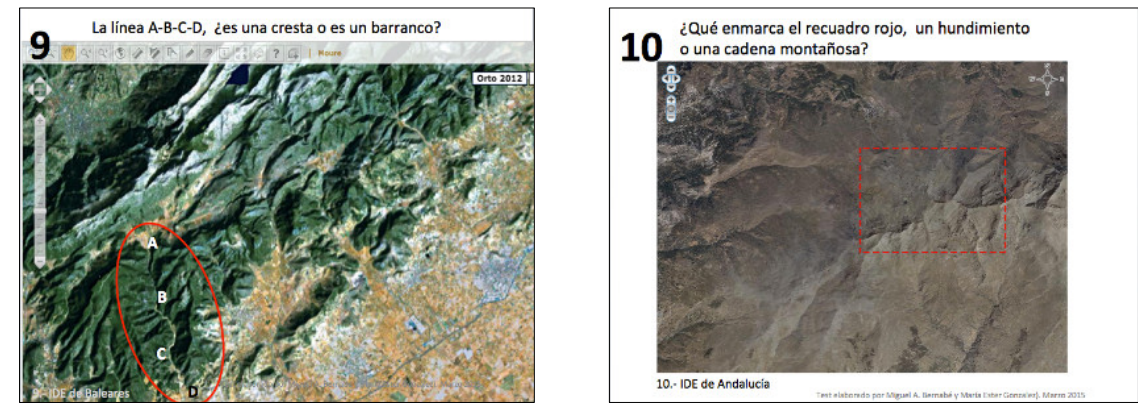

Figura 62. La línea $\mathrm{ABCD}$ ¿es una Figura 63. El rectángulo, ¿enmarca un cresta o un barranco? hundimiento o una cadena montañosa? 


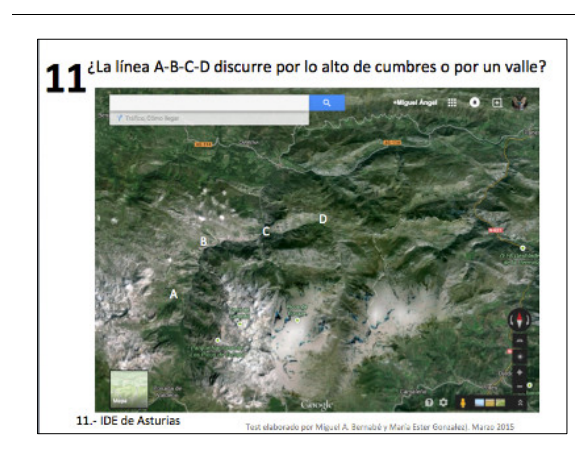

Figura 64. La línea ABCD ¿discurre por las cumbres o por el valle?

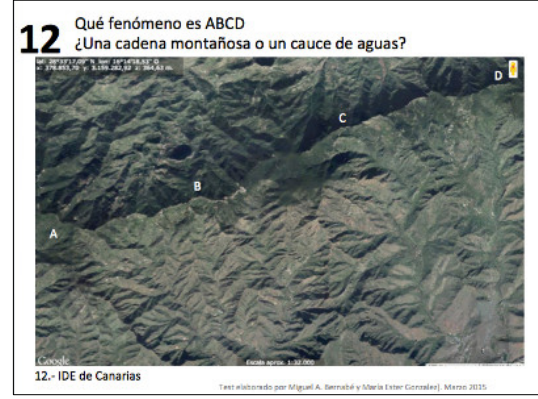

Figura 65. La línea ABCD ¿es una cadena montañosa $o$ un cauce de aguas?
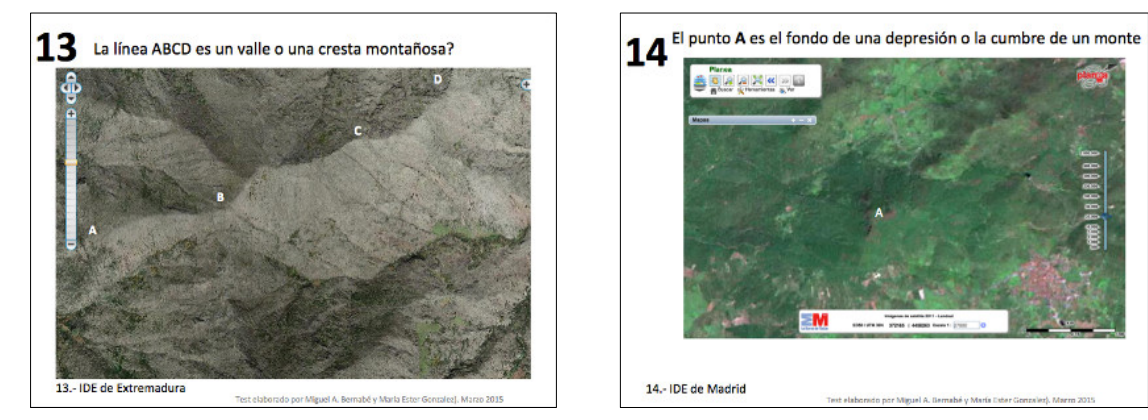

Figura 66. La línea ABCD ¿es un valle Figura 67. El punto A ¿es una depresión o una cresta? o la cumbre de un monte?
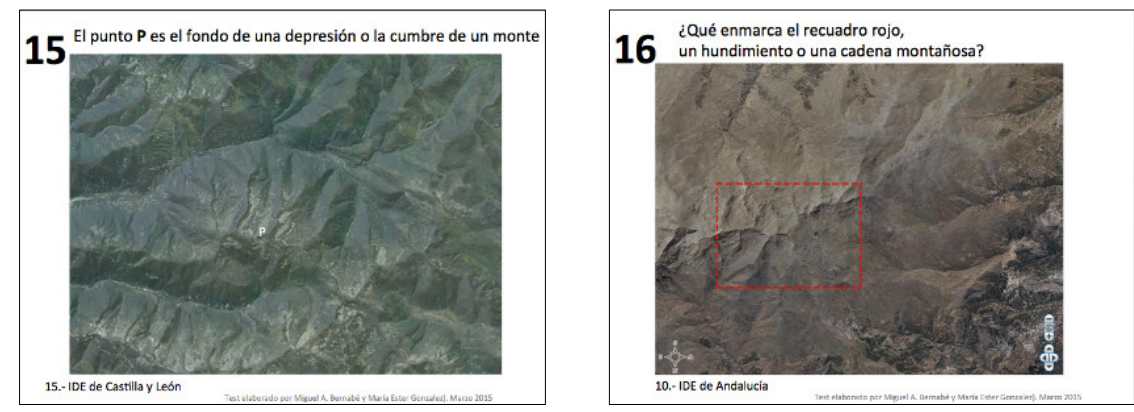

Figura 68. El punto $\mathrm{P}$ ¿es el fondo de Figura 69. El recuadro ¿enmarca una una depresión o la cumbre de un depresión o una cadena montañosa? monte? 


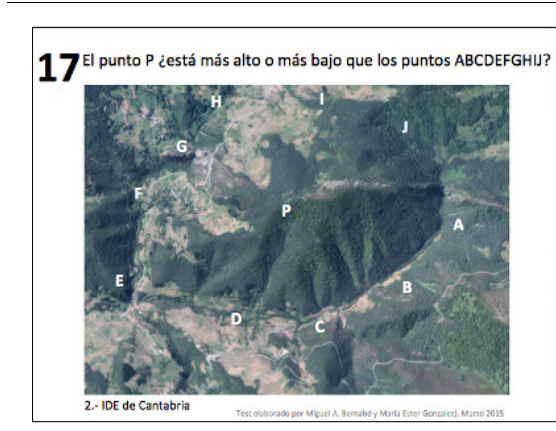

Figura 70. ¿Está el punto $\mathrm{P}$ más alto $\mathrm{O}$ más bajo que los puntos $\mathrm{ABCDEFGHI}$ ?

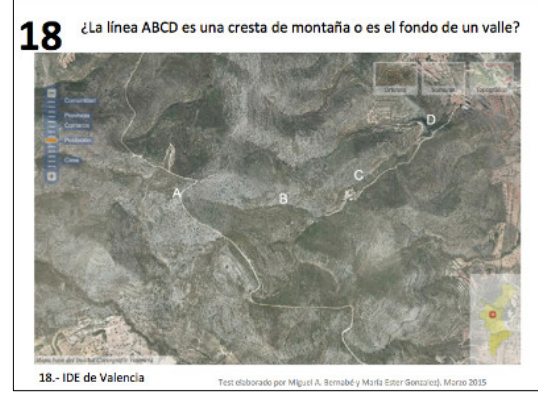

Figura 71. ¿La línea $\mathrm{ABCD}$ es una cresta o el fondo de un valle?

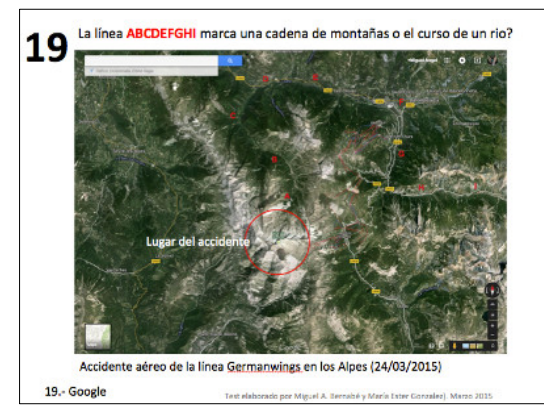

Figura 72. La línea A,..,I, ¿marca una cadena montañosa o el curso de un rio?

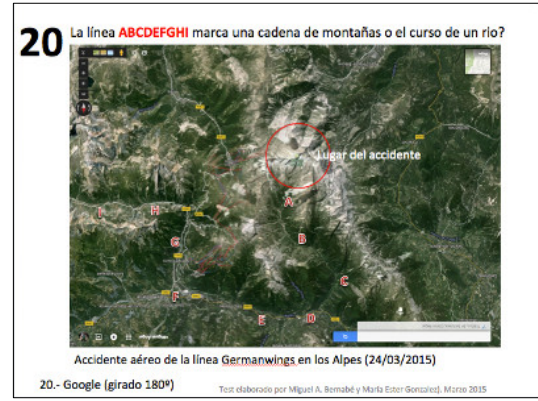

Figura 73. La línea A,..,I, ¿marca una cadena montañosa o el curso de un rio?

\section{ANÁLISIS ESTADÍSTICO DE RESPUESTAS}

\section{IV.1 Software utilizado}

Se ha utilizado para los cálculos el programa SPSS versión 19, y Excel 2007.

\section{IV.2 Muestra}

Es de tipo accidental, es decir, se ha presentado la encuesta vía web y los participantes son voluntarios. En los resultados preliminares que se ofrece han participado 239 personas de 23 países de Europa, América y Oceanía. Los participantes tienen mayoritariamente formación universitaria. Se han eliminado las respuestas incompletas quedando finalmente una muestra válida de 208 personas.

La participación por sexos es de 56\% varones y $44 \%$ mujeres. 
La edad de los participantes discurre entre 21 y 79 años con una media de 39 años (hay también un participante con 12 años).

El 94\% de los participantes eran diestros y el 6\% zurdos.

El $57 \%$ eran americanos y el $42 \%$ eran europeos con incidencias menores de Oceanía.

E1 77\% de los participantes era licenciado, ingeniero o superios; el 23\% era diplomado; el 1\% eran bachilleres o menos.

\section{IV.3 Resultados}

Hay un 33,8\% de aciertos en la lectura del relieve de las imágenes tal como se muestran en los visualizadores.

Hay un $84,1 \%$ de aciertos cuando se invierten las imágenes proporcionadas por los visualizadores o cuando se introduce una corrección para evitar el relieve inverso.

Hay un $6 \%$ mayor de aciertos en los varones que en las mujeres.

Al aumentar la edad decrece el número de aciertos a una velocidad aproximada del $3 \%$ cada 10 años.

Hay un 1\% mayor de aciertos en zurdos que en diestros.

Hay un $1 \%$ mayor de aciertos en licenciados/doctores que en diplomados.

\section{CONCLUSIONES}

Aunque la prueba no está terminada y el grupo de participantes tiene una tendencia hacia personas con formación universitaria, del recorrido realizado por los visualizadores de las IDE de España y de los resultados preliminares puede afirmarse que:

1. Casi la mitad de los visualizadores de las IDEE utilizan imágenes aéreas (ortofotos o imágenes satelitales) como «cartografía base» para mostrar el relieve o sobre la que mostrar otras características del territorio.

2. El pseudorrelieve puede observarse en la mayoría de los visualizadores de las IDEE cuando se utilizan imágenes aéreas.

3. Sólo hay un visualizador de las IDEE que disponga de herramientas para evitar el pseudorrelieve de las imágenes aéreas.

4. Más del $65 \%$ de los usuarios de los visualizadores de las IDEE perciben incorrectamente el relieve. 
5. Cuando se aplica alguna corrección de las referidas en la literatura, el porcentaje de usuarios que perciben incorrectamente el relieve baja por debajo del $16 \%$.

6. No existen diferencias reseñables en la percepción del relieve debidas al grado de formación, a la lateralidad del individuo o a la edad.

7. Hay un incremento del $6 \%$ en la percepción del pseudorrelieve en las mujeres respecto a los hombres.

\section{AGRADECIMIENTOS.}

Los autores expresan su agradecimiento al programa de Becas Prometeo de la Secretaria Nacional de Educación Superior, Ciencia y Tecnología (SENESCYT) de Ecuador, en cuyo contexto se ha desarrollado esta colaboración entre el Instituto Geográfico Militar de Ecuador y la Universidad Politécnica de Madrid. Se agradece asimismo la colaboración desinteresada de los más de dos centenares de participantes en el test que ha evidenciado los resultados.

\section{BIBLIOGRAFÍA}

ARnHeIM, R. (1976): «The Perception of Maps». Cartography and Geographic Information Science 3, 5-10.

doi: http://www.tandfonline.com/ doi/abs/10.1559/152304076784080276

BERnABÉ-PovedA, M. A. y ÇÖLTEKIN, A. (2014): «Prevalence of the terrain reversal effect in satellite imagery». Journal of Digital Earth, Mach 2014, 640-655. Taylor $\&$ Francis International. http://dx.doi.org/10.1080/17538947.2014.942714.

BERNABÉ-PovedA, M. A. y GonZÁLEZ, M.E. (2015): «Los relieves invertidos en los Globos Virtuales». Ágora de Heterodoxias. Feb-Jul, 72-89. Ed. Universidad Centroccidental «Lisardo Alvarado». Venezuela

BERnABÉ-PovedA, M. A.; SÁnCHEZ-ORTEGA, I. y ÇÖLteKIn, A. (2011): «Techniques for highlighting relief on orthoimagery». Ed. Elsevier. Procedia. Social and Behavioral Sciences. Vol 21. 2011, 356-352

doi: 10.1016/j.sbspro.2011.07.028. Septiembre 2011.

IMHOF, E. (1967): «Shading and Shadows». In Cartographic Relief Representation, edited by H. J. STEWARD, 159-212. Redlands, CA: ESRI Press.

IMHOF, E. (1982): Cartographic Relief Presentation. STEWARD, H.J. (ed). Berlin, New York. De Gruyter

PAin, C. F., y Clarke, J. D. A. (2009): «Relief Inversion: Australian Analogs of a Common Feature of Martian Landscape Evolution». En 40th Lunar and Planetary Science Conference, 5-6, The Woodlands, TX, March 23-27.

SARAF, A. K.; DAS, J.D.; AGARWAL, B. y SundARAM, R.M. (1996): «False Topography Perception Phenomena and Its Correction». International Journal of Remote Sensing 17, 3725-3733.

doi: http://dx.doi.org/10.1080/01431169608949180 
SARAF, A. K.; ShInA, S. T.; GHOSh P. y ChOurdhury S. (2007): «A New Technique to Remove False Topographic Perception Phenomenon and Its Impacts in Image Interpretation». International Journal of Remote Sensing 28, 811-821. doi: http://dx.doi.org/10.1080/01431160701269796.

Wood, M. (1968): «Visual Perception and Map Design». The Cartographic Journal 5, 54-64.

doi: http://dx.doi.org/10.1179/caj.1968.5.1.54

WU, B.; LI, H. y GAO, Y. (2013): «Investigation and Remediation of False Topographic Perception Phenomena Observed on Chang'E-1 Lunar Imagery». Planetary and Space Science 75, 158-166. doi:10.1016/j.pss.2012.10.018.

Zhou, A.; ZHANG, X. y GAO, Y. (2006): «DEM Terrain Reversal». Geography and Geo-Information Science 22, 42-44. 